\section{The role of social capital in the health development of children}

\section{ealth status and behaviours are
strongly linked with both wellbeing strongly linked with both wellbeing and quality of life, as docum} However, determining how to improve health in individuals and societies is mo uncertain. It is questionable whether wealth Interestingly, research shows the not all weathy and advanced countries rank at the top of the global league table of happiness The Scandinavian countries tend to rank highly in this respect. These countries are characterised by a comparatively high level of wealth but also a high level of life expectancy low levels of corruption and a sense of belonging, which together facilitate greater trust and solidarity. It is likely that the degree of social capital also contributes to this sense of cohesion and connectedness, a concept which has become increasingly studied wit in

DEFINING SOCIAL CAPITAL The concept of social capital beca Putnam and was initilly applied to political science pertaining to shared values and local networks. Later, Bourdieu's work was rediscovered, who addresses social capital on the level. of individuals. Today, there is a lack of consensus about how social capital should be defined.

Halpern proposed that social capital exists at three different levels: the micro level (family), the meso level (neighbourhood) The key feature of social capital is its focus on the relationships among individuals. Unlike human capita (which focuses on individual abilities) and economic capital (which refers to possession), social capital addresses the gives the person an gives hison anvage, hrough and trust These, in turn improve life satisfaction and wellbeing

Three forms of social capital have been defined by Putnam: bonding, bridging and linking. Bonding refers to strong direct links between individuals in a similar socio-demographic and socio-economic or socio-cultural environment. Bridging pertains to comparatively weak horizonta connections between different groups, which originate from a similar social class. Linking refers to vertical links between privileged and less privileged groups. Although the concept of social capital is widely used in social science resear the study of children. An used in and Sven Stadtmïller addressed this gap in the literature by exploring whether an intrapersonal change in social capital affects children's health status and behaviour over time. They used longitudinal panel-data (long-term data), rather than cross-sectional data, which looks at data at one point in time, so that they could determine if the effect of social capital on health was causal. the results varied across different socio

\section{APPLYING SOCIAL}

\section{CAPTAL TOCHILDREN}

DAPITAL TOCHILREN

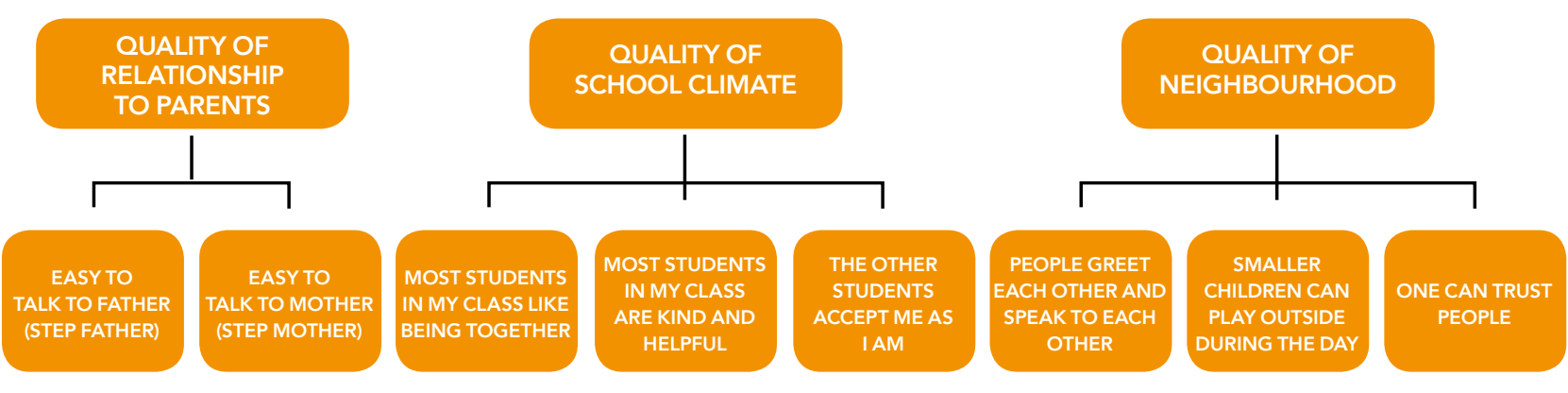

capital are applicable to this group, as long as adjustments are made for different ages. Family ties and frendships (bonding) amongst similar socio-demographic grou
throughout childhood.

However, children also make connections with those from different backgrounds when they join organisations and

associations, such as schools and sports clubs, which is characteristic of bridging. The linking form of social capital is more challenging for children as these are inherently hard to establish and might even have a marginalising effect of those from less privileged backgrounds because children can often decipher different social backgrounds.

When applying social capital in children, it is most useful to consider the concept on the individual level. This is because the other levels are largely unrecognised in this age group. The individualistic approach can be conceptualised with which states: 'Social capital is the aggregate of the actual or potentit resources which are linked to possession of a durable network of more or less institutionalized relationships of mutu acquaintance and recognition.' For children particularly, the concept can be viewed as a trust-based network, which can be accessed when social support is needed. Children cannot usually change their personal circumstances so they must turn to trusted others, particularly adults.

ased on the established link between social capital and health in adults, a similar relationship might be expected to exist in children. This was the focus Sthe work of Andreas Klocke and Sven with regard to this relationship. The first is that children with a high amount of social capital show a better health

with trust in children. In childhood and adolescence, individuals usually gain trust

It is questionable whether health is determined solely by income or wealth. status and health behaviour. Secondly, researchers hypothesised that children who gain more social capital over time should see significantly improved health. The third prediction was that social capital is a causal protective factor in the health development of children, demographic groups.

\section{MEASURING SOCIAL}

\section{CAPITAL IN CHILDREN}

Klocke and Stadtmüller used three indicators to measure social capital in children, which were the quality of climate and quality of the neighbourhood. These elements were selected because they were felt to be most strongly linked

this relationship is of high importance. children because it is where they spend most of their day and involves a high amount of socialisation. The quality of the school environment was measured by relying on the perceived relationships with other pupils (mutual trust). The third element considered important was the quality of the immediate neighbourhood because it concerns security. Health was determined by asking children to rate their general health on a five-point scale. They were also asked about sleep, concentration levels, perceived of soft drinks and vegetables. Socio-

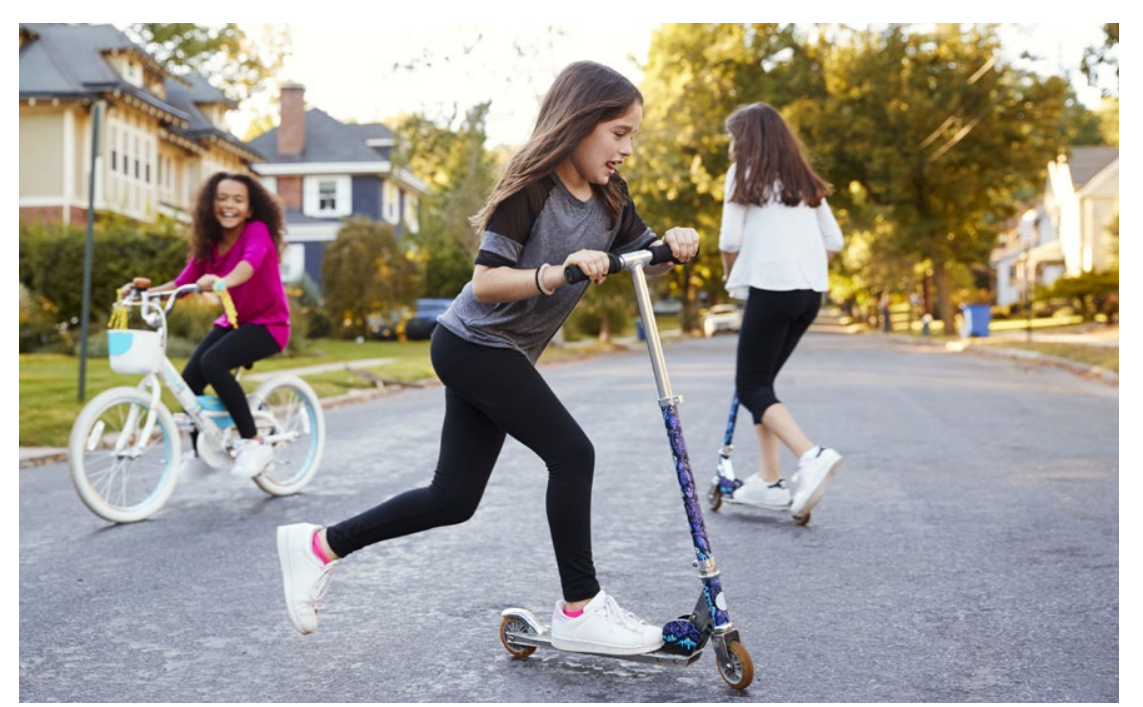
School is also highly significant for nos and wellbeing, and consumpton 
EFFECTS OF SOCIAL CAPITAL AND FAS ON HEALTH Fixed effects regression models

\begin{tabular}{|lccccccccc} 
& \multicolumn{3}{c}{ Social Capital } & \multicolumn{3}{c}{ Family Affluence } & \multicolumn{2}{c}{ Constant } \\
& $\mathrm{b}$ & se & $\mathrm{p}$ & $\mathrm{b}$ & se & $\mathrm{p}$ & $\mathrm{b}$ & se \\
\hline Sleep difficulties & -.164 & $(.018)$ & $* * *$ & -.017 & $(.019)$ & & 2.94 & $(.202)$ \\
\hline Could not concentrate well & -.202 & $(.016)$ & $* * *$ & .013 & $(.016)$ & & 2.62 & $(.172)$ \\
\hline Feeling fit and comfortable & .355 & $(.018)$ & $* * *$ & .019 & $(.019)$ & & 1.94 & $(.196)$ \\
Consumption of Coke and lemonade & -.091 & $(.015)$ & $* * *$ & -.005 & $(.016)$ & & 2.01 & $(.170)$ \\
\hline Consumption of salads and vegetables & .152 & $(.016)$ & $* * *$ & .107 & $(.017)$ & & 2.22 & $(.176)$ \\
\hline
\end{tabular}

An (within-children) increase in the volume of social capital reduces

(mental) health problems and improves health behaviour

- Changes in FAS hardly play any role

status, as indicated by higher perceived asking about family cars, holidays, and whether there were books at home.

\section{OCIAL CAPITAL I}

\section{THE HEALTH OF CHILDREN}

Researchers found that social capital

fitness and wellbeing levels and greater consumption of vegetables. In addition, higher social capital was linked with

behaviour, with the greatest effect for the different features of mental health fitness and wellbeing) and smallest for physical health behaviour (drinking sof drinks and eating vegetables).

The study also found that a change in social capital was significantly associated with the health and health behaviour of a child. Greater social capital over time was linked with increased perceived fitness and wellbeing, fewer problems

Children cannot usually change their

personal circumstances so they must turn to trusted others, particularly adults.

ewer problems with concentratio drinks. With the exception of soft dink consumption, social capital was a greater predictor than family affluence on health. Overall, the amount of socia capital was highly associated with health status, mental health and health
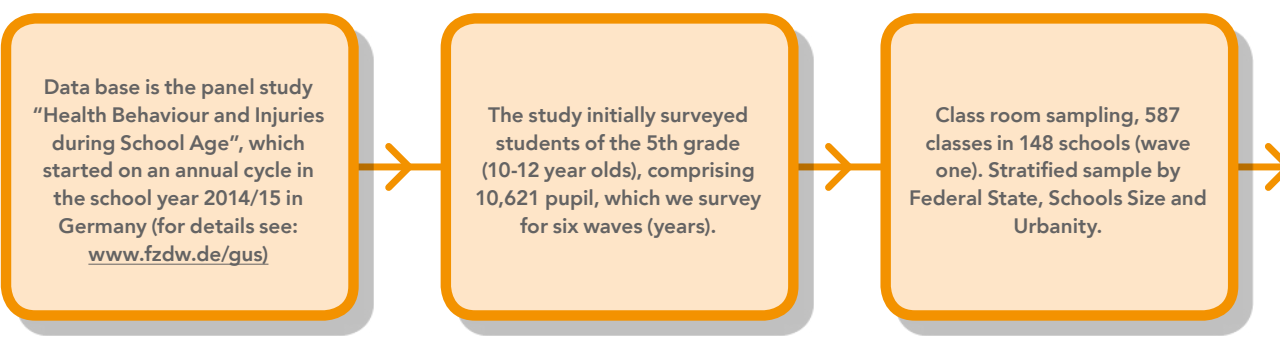
RESEARCH DESIGN this holds true over time. In addition all three components of social capital quality of school climate and quality of neighbourhood) were equally important

\section{THE FUTURE}

Klocke and Stadtmüller have powerful tool in the analysis of health and health behaviour in childhood. This is especially true as children are in the process of growing up. The research change in social capital over time has a significant effect on the health and health can thus be conceptualised acial capisal factor affecting health development in children, which operates independently of socio-demographic status. In order the health of children in important to establish and maintain social networks and resources (social capital) rather than merely providing financial assistance. for

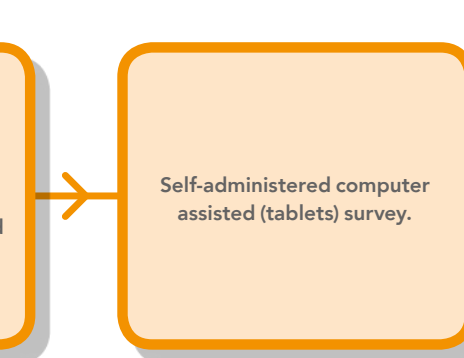

\section{Behind the Research}

\section{Andreas}

Klocke

T: \pm E: andreas.klocke@tzdw.de

\section{Research Objectives}

Andreas Klocke and Sven Stadtmüller aim to determine a causal effect of social capital on the health of children and wheth
socio-demographic groups.

\section{Detail}

Frankfurt University of Applied Sciences, Nibelungenplatz 1 , 60318 Frankfurt, Germany

Bio

An the Research Centre on Demographic Change at Frankfurt University of Applied Sciences, Germany. His main areas of research are social inequalities, youth, health and demography.

Sven Stadtmüller is Senior Researcher at the Research Centre on Demographic Change at Frankfurt University of Applied Sciences and at GESIS - Leibniz-lnstitute for he Social Sciences. His main areas of research are survey

\section{Funding}

Social Accident

Insurance (DGUV)
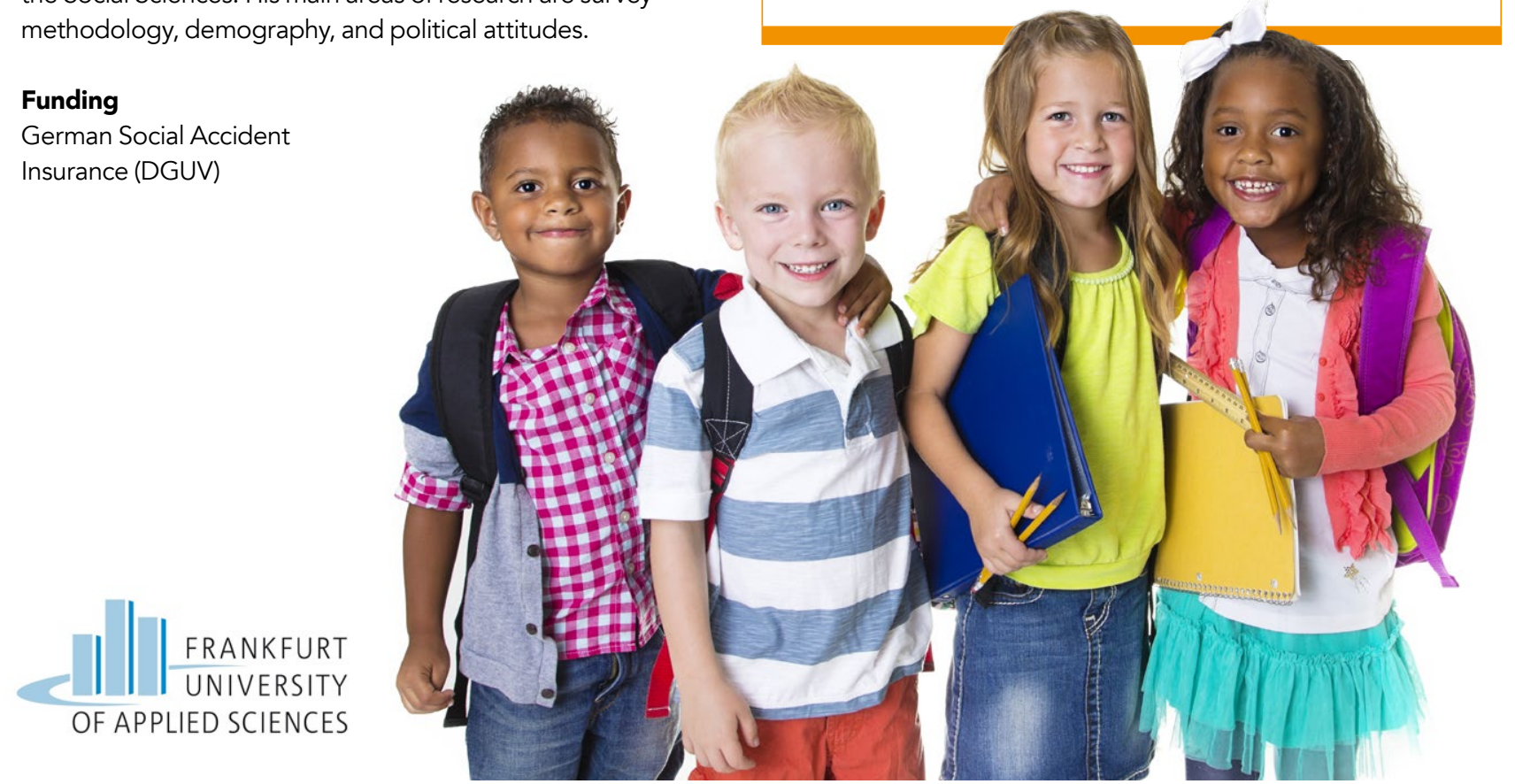

Sven Stadtmüller E: sven.stadtmueller@fzdw.de
T: $+00496915333187 \quad$ W: fzdw.de

\section{References}

Klocke, A., \& Stadtmüller, S. (2018). 'Social capital in the health development of children'. Child 1 ind
org $1007 /$ s $12187-018-9583-y$

\section{Personal Response}

Does the relationship between social capital in children and health appear to be linear or is there a

II No, there is no threshold which we have to overiump in social capital are powerful. Furthermore, all socioto before we see a positive effect of social capital on the demographic groups are benefitting from a higher 